This item was submitted to Loughborough's Research Repository by the author.

Items in Figshare are protected by copyright, with all rights reserved, unless otherwise indicated.

\title{
Passive suspensions for ride quality improvement of two-axle railway vehicles
}

PLEASE CITE THE PUBLISHED VERSION

https://doi.org/10.1177/0954409713511592

PUBLISHER

SAGE @ IMechE

VERSION

AM (Accepted Manuscript)

\section{PUBLISHER STATEMENT}

This work is made available according to the conditions of the Creative Commons Attribution-NonCommercialNoDerivatives 4.0 International (CC BY-NC-ND 4.0) licence. Full details of this licence are available at: https://creativecommons.org/licenses/by-nc-nd/4.0/

\section{LICENCE}

CC BY-NC-ND 4.0

\section{REPOSITORY RECORD}

Jiang, Jason Z., Alejandra Z. Matamoros-Sanchez, Argyrios C. Zolotas, Roger M. Goodall, and Malcolm C. Smith. 2019. "Passive Suspensions for Ride Quality Improvement of Two-axle Railway Vehicles". figshare. https://hdl.handle.net/2134/26638. 


\title{
Passive suspensions for ride quality improvement of two-axle railway vehicles
}

\author{
Jason Zheng Jiang*, Alejandra Z Matamoros-Sanchez ${ }^{\dagger}$, Argyrios Zolotas ${ }^{\natural}$, \\ Roger M Goodall ${ }^{\dagger}$ and Malcolm C Smith*
}

\begin{abstract}
*Department of Engineering, University of Cambridge, Cambridge, CB2 1PZ, UK,
email: $\{z \cdot j$ iang, mcs $\} @ e n g \cdot a c m \cdot a c \cdot u k$

${ }^{\dagger}$ Department of Electronic and Electrical Engineering, Loughborough University, Leicestershire, LE11 3TU,

UK, email: \{A.Z.Matamoros-Sanchez, R.M.Goodall\}@lboro.ac.uk

${ }^{\natural}$ Department of Engineering and Design, University of Sussex, Sussex House, Brighton, BN1 9RH, UK, email:

$\{$ a.zolotas\}@sussex.ac.uk
\end{abstract}

\begin{abstract}
The aim of this paper is to investigate the possibility of improving the ride quality of a two-axle railway vehicle with single-stage suspension by means of passive suspensions employing the inerter device. The inerter is a mechanical one-port element analogous to the capacitor in electrical circuits. The goal is to improve the ride quality in both the vertical and lateral motion in response to track irregularities. Performance benefits for several simple passive suspension layouts are demonstrated here in comparison with the conventional scheme. The elastic effects of the damper and inerter device are then taken into consideration for practical purpose. The optimum parameter values of the damper, inerter and the parameters representing the elastic effects provide guidance for mechanical design purposes.
\end{abstract}

Keywords: Inerter, train suspension, passive network, ride quality, railway vehicle 


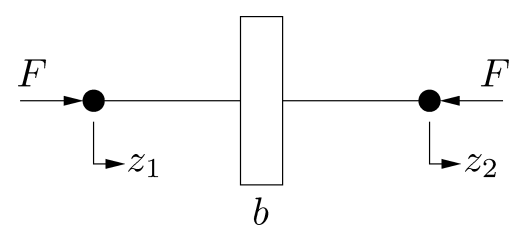

Fig. 1 (Ideal) inerter modelling symbol.

\section{Introduction}

This paper considers the application of advanced passive suspension to two-axle single-stage railway vehicles. Such vehicles dispense with the bogies and the secondary suspension and therefore offer simpler mechanical constructions which is translated to $30-35 \%$ reductions in vehicle weight. Despite the advantage, widespread use of the vehicle has been limited because the single stage of suspension leads to an unsatisfactory ride quality. This applies both to the lateral and vertical dynamics. Whole-body vibrations in trains are known to affect the performance of sedentary actions such as reading, writing, sketching, working on laptops, etc [1]. Goodall et al. ([2], [3]) studied the use of an active suspension to overcome these difficulties, however this paper investigates the prospects of introducing inerters, together with the traditional spring and damper, i.e. configuring a mechanical compensator without the need for active elements. This paper extends the work of [4] on the vertical and considers the dynamics in the lateral direction.

The inerter [5] is a mechanical two-terminal element with the property that the applied force at the terminals is proportional to the relative acceleration across the terminals, i.e. $F=b\left(\ddot{z}_{1}-\ddot{z}_{2}\right)$, in the notation of Figure 1, where $b$ is the constant of proportionality in kilograms, called inertance. The inerter, together with spring and damper, provides a complete analogy between mechanical and electrical elements, which allows arbitrary passive mechanical impedances to be synthesised. Applications of the method to vehicle suspension [6, 7, 8], control of motorcycle steering instabilities [9, 10], vibration absorption [5] and building suspension control $[11,12]$ have been identified. The inerter is now been deployed in suspension systems in motor racing $[13,14]$.

Some of the possible applications of the inerter device to the rail suspensions have been explored in $[15,16$, 17, 4]. However, non-ideal behaviour of the damper and inerter devices (e.g. compliance effects) have not been considered in this literature except [15], in which some parasitic effects of the inerter device were taken 
into account for a bogied railway vehicle vertical model. A preliminary study of ride comfort improvement in the vertical direction for a two-axle railway vehicle has been presented in [4]. The aim of this paper is to study how the ride quality in both lateral and vertical directions of a single suspension two-axle railway vehicle might be improved. Some beneficial layouts incorporating inerters are proposed and the related improvements are discussed. For the parasitic effects of both dampers and inerters, we carry out a series of optimisations in a systematic manner. For beneficial layouts, the effect on the suspension deflection is also considered. Since throughout the investigation, the static stiffness is kept at its nominal values in both lateral and vertical directions, together with good overall system damping, the suspension deflections when the vehicle negotiates deterministic track features (e.g. a gradient and a curve) are similar to the default values. For brevity, we do not include these results in the present paper. It needs to be pointed out that, although it is recognised that flexible modes of the vehicle are important when additional components are added across the suspension, in the present paper vehicle body flexible modes are excluded so that the fundamental potential of the inerter can be assessed.

This paper is structured as follows. Section 2 introduces the candidate suspension layouts we investigate. The potential improvement of ride quality in the lateral and vertical direction are investigated in Section 3 and 4, respectively. Section 5 presents a complete summary of the results and some general remarks.

\section{Candidate Suspension layouts}

In this paper, we first consider four simple layouts shown in Figure 2. In order to reveal the general trend of the relationship between suspension layouts, parameter values and ride quality, the only constraint on S1-S4 is that the element values be non-negative. No parasitic effects are considered. These layouts are relatively simple to realise in practice $[18,19,20]$. S1 models a conventional parallel spring-damper layout when $k_{1}=\infty$. S2-S4 each includes one or two inerters with $\mathrm{S} 1$. The mechanical admittance $Y(s)$ for these layouts can be calculated respectively, e.g. for S4:

$$
Y(s)=\frac{K}{s}+\left(\frac{s}{k_{1}}+\frac{1}{c_{1}}+\frac{1}{b_{1} s}\right)^{-1}+b_{2} s .
$$




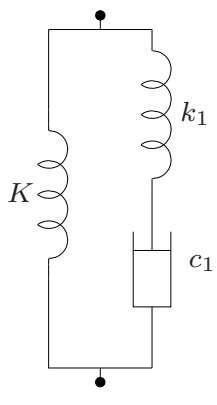

S1

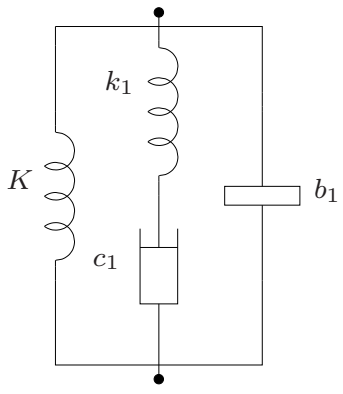

S2

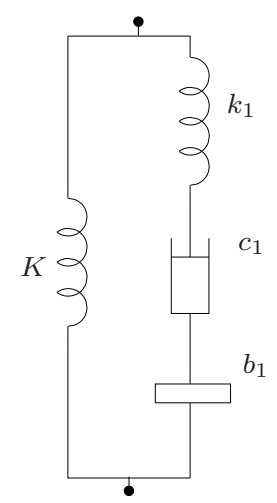

S3

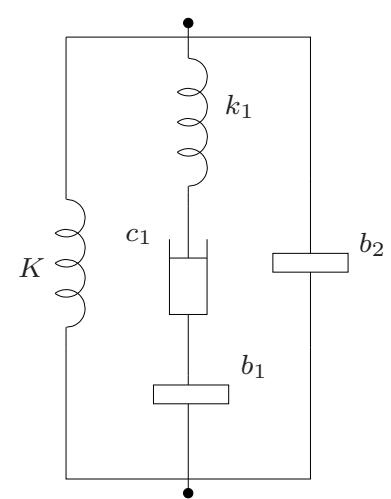

S4

Fig. 2 Passive suspension layouts $\mathrm{S} 1-\mathrm{S} 4$ of theoretical interest.

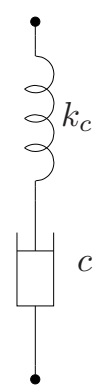

(a)

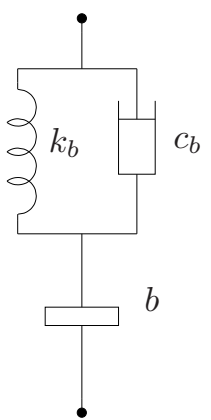

(b)

Fig. 3 Damper and inerter devices with elastic effects included.

In order to make the suspension models closer to real suspension devices, we now include an end-stiffness in the damper and a "buffer" network for the inerter devices consisting of a spring and damper in parallel (reflecting the fact that a small amount of dissipation will always be present in practical inerters), both of which we refer to as elastic effect (Figure 3). It can be seen from [21] that the end-stiffness for the secondary lateral damper of a bogied vehicle equals $5 \times 10^{6} \mathrm{~N} / \mathrm{m}$. Here we make a conservative assumption that $k_{c}$ and $k_{b}$ are no greater than $k_{\max }$, where $k_{\max }=3.5 \times 10^{6} \mathrm{~N} / \mathrm{m}$. The dissipation effect of an inerter device has been studied in [15], where a damper in parallel with the end-stiffness has been included. The value of the damping effect was estimated to be $3.2 \times 10^{3} \mathrm{Ns} / \mathrm{m}$. Here, we select $c_{b}$ to be no greater than $c_{\max }=5 \times 10^{3} \mathrm{Ns} / \mathrm{m}$. Figure 4 presents $\mathrm{S} 1-\mathrm{S} 4$ with elastic effects included. It should be noted that the spring $k_{1}$ has been excluded for these layouts, this is because if the optimisation results give a very low value of the end-stiffness, an extra spring can then be included. 


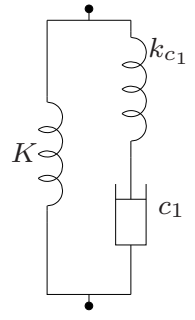

(a) $\mathrm{S} 1^{\prime}$

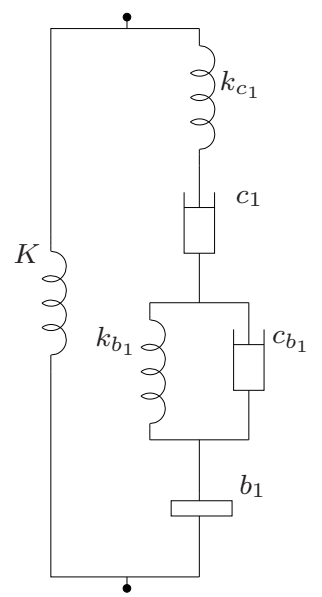

(c) $\mathrm{S} 3^{\prime}$

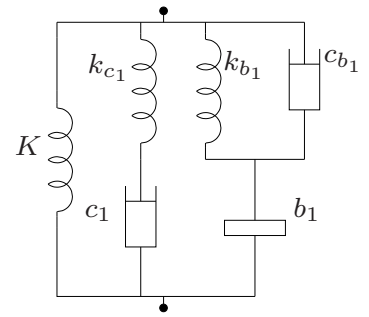

(b) $\mathrm{S}^{\prime}$

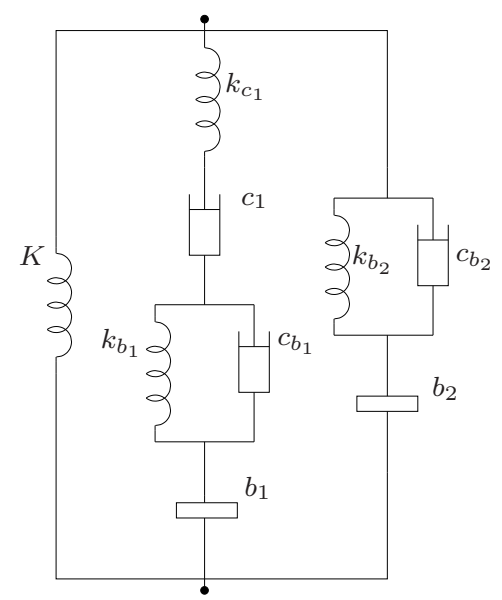

(d) $\mathrm{S} 4^{\prime}$

Fig. 4 Passive suspension networks for layouts S1-S4 including elastic effects, where $k_{c_{1}}, k_{b_{1}}, k_{b_{2}} \leq k_{\max }$; $c_{b_{1}}, c_{b_{2}} \leq c_{\max }$ 


\section{Passive Suspensions in the Lateral Direction}

In this section, we present the potential ride quality improvement in the lateral direction by passive suspensions incorporating inerter. The plan view model we used here is a slight modification from [22]. The passive suspension in the longitudinal direction has been included. The result shows big potential improvement by the unconventional suspension layouts we proposed.

\subsection{Two-Axle Railway Vehicle Plan View Model and Track Input}

As shown in Figure 5, the plan view model consists of one vehicle body and two solid axle wheelsets. Longitudinal and lateral connections between wheelsets and vehicle body have been included. Vertical and roll modes are not modelled, and longitudinal connections are included only for their contribution to the yaw modes. Hence the model contains six degrees-of-freedom: lateral and yaw modes for each wheelset $\left(y_{w 1}, \theta_{w 1}, y_{w 2}, \theta_{w 2}\right)$ and for the vehicle body $\left(y_{v}, \theta_{v}\right)$. The mathematical model is described by the following equations

$$
\begin{gathered}
m_{w} s^{2} \hat{y}_{w 1}=2 s Y(s)\left(\hat{y}_{v}-\hat{y}_{w 1}\right)-\frac{2 f_{22}}{V} s \hat{y}_{w 1}+2 f_{22} \hat{\theta}_{w 1}+2 s Y(s) l_{w x} \hat{\theta}_{v}, \\
I_{w} s^{2} \hat{\theta}_{w 1}=-\frac{2 f_{11} l_{w y}^{2}}{V} s \hat{\theta}_{w 1}-\frac{2 f_{11} \lambda l_{w y}}{r_{0}} \hat{y}_{w 1}+2\left(K_{x}+s C_{x}\right) l_{x}^{2}\left(\hat{\theta}_{v}-\hat{\theta}_{w 1}\right)-\frac{2 f_{11} \lambda l_{w y}}{r_{0}} \hat{y}_{t 1}, \\
m_{w} s^{2} \hat{y}_{w 2}=2 s Y(s)\left(\hat{y}_{v}-\hat{y}_{w 2}\right)-\frac{2 f_{22}}{V} s \hat{y}_{w 2}+2 f_{22} \hat{\theta}_{w 2}-2 s Y(s) l_{w x} \hat{\theta}_{v}, \\
I_{w} s^{2} \hat{\theta}_{w 2}=-\frac{2 f_{11} l_{w y}^{2}}{V} s \hat{\theta}_{w 2}-\frac{2 f_{11} \lambda l_{w y}}{r_{0}} \hat{y}_{w 2}+2\left(K_{x}+s C_{x}\right) l_{x}^{2}\left(\hat{\theta}_{v}-\hat{\theta}_{w 2}\right)-\frac{2 f_{11} \lambda l_{w y}}{r_{0}} \hat{y}_{t 2}, \\
m_{v} s^{2} \hat{y}_{v}=2 s Y(s)\left(\hat{y}_{w 1}-\hat{y}_{v}\right)+2 s Y(s)\left(\hat{y}_{w 2}-\hat{y}_{v}\right) \\
I_{v} s^{2} \hat{\theta}_{v}=2 s Y(s) l_{w x}\left(\hat{y}_{w 1}-\hat{y}_{v}\right)+2 s Y(s) l_{w x}\left(\hat{y}_{v}-\hat{y}_{w 2}\right)+2\left(K_{x}+2 C_{x}\right) l_{x}^{2}\left(\hat{\theta}_{w 1}-\hat{\theta}_{v}\right) \\
\quad+2\left(K_{x}+s C_{x}\right) l_{x}^{2}\left(\hat{\theta}_{w 2}-\hat{\theta}_{v}\right)-4 s Y(s) l_{w x}^{2} \hat{\theta}_{v},
\end{gathered}
$$

where $\hat{y}_{w 1}$ denotes the Laplace transform of $y_{w 1}(t)$, etc, and parameter values are shown in Table 1 . It is a slight modification of the model introduced in $[2,22]$ with some parameter values being modified and with suspension in the yaw direction added. Because our focus is on improving the ride comfort for straight running without affecting the curving performance, we consider using the inerter device only in the lateral 


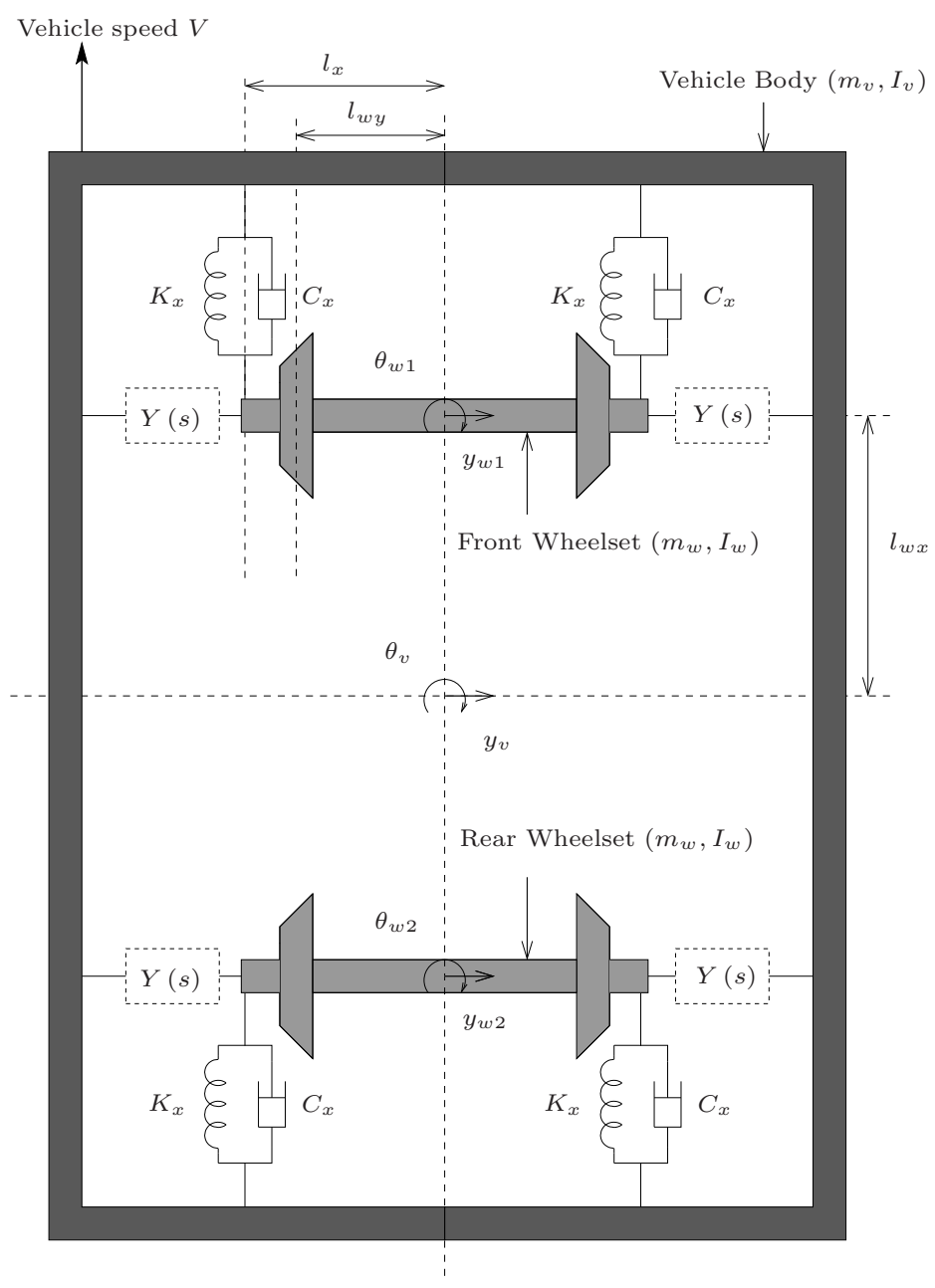

Fig. 5 Two-axle vehicle plan view model. 
direction and keep the suspension in the longitudinal direction fixed.

A state-space form can be readily derived from Equations (1) - (6) as given in (7):

$\dot{x}=A x+B w$,

where

$$
\begin{aligned}
x & =\left[\dot{y}_{w 1}, y_{w 1}, \dot{\theta}_{w 1}, \theta_{w 1}, \dot{y}_{w 2}, y_{w 2}, \dot{\theta}_{w 2}, \theta_{w 2}, \dot{y}_{v}, y_{v}, \dot{\theta}_{v}, \theta_{v}\right]^{T}, \\
w & =\left[y_{t 1}, y_{t 2}\right]^{T} .
\end{aligned}
$$

The straight track lateral stochastic inputs $\left(y_{t 1}, y_{t 2}\right)$ used in this paper are of a broad frequency spectrum with a relatively high level of irregularities. Here $y_{t 1}(t)$ denotes the output of a filter $H_{1}(s)=$ $\left(21.69 s^{2}+105.6 s+14.42\right) /\left(s^{3}+30.64 s^{2}+24.07 s\right)$ whose input is a process with a single sided power spectral density

$$
S_{y}\left(f_{s}\right)=\frac{A_{l}}{f_{s}^{2}},
$$

in which $A_{l}$ is the track roughness factor, and $f_{s}$ is a spatial frequency in cycles/metre. The idea is to provide an approximation to the $1 / f^{3}$ power spectrum [23]. The body lateral acceleration of the carriage is quantified in terms of the root mean square (r.m.s.) acceleration $J_{1, y}$, and can be evaluated by the covariance method, time domain simulation method and frequency calculation method. For the frequency calculation, $J_{1, y}$ is expressed by

$$
J_{1, y}^{2}=\int_{0}^{\infty}\left|G_{\dot{y}_{t 1} \rightarrow \ddot{y}_{v}}(j \omega) H(j \omega)\left(1+\mathrm{e}^{-j \omega T_{d}}\right)\right|^{2} S_{\dot{y}} d \omega \approx \Delta \omega S_{\dot{y}} \sum_{\omega=0.01}^{30 \pi}\left|G_{\dot{y}_{t 1} \rightarrow \ddot{y}_{v}}(j \omega) H(j \omega)\left(1+\mathrm{e}^{-j \omega T_{d}}\right)\right|^{2},
$$

where

$$
S_{\dot{y}}=4 \pi^{2} A_{l} V,\left(\mathrm{~ms}^{-1}\right)^{2}(\mathrm{rad} / \mathrm{s})^{-1},
$$

$T_{d}$ equals $2 l_{w x} / V$ seconds, which is the time delay $\left(T_{d}\right)$ of the track input between the front and rear wheelsets, and $G_{\dot{y}_{t 1} \rightarrow \ddot{y}_{v}}$ represents the transfer function from the track velocity input $\dot{y}_{t 1}$ to the lateral body acceleration $\ddot{y}_{v}$. The nominal speed is taken to be $31 \mathrm{~ms}^{-1}$ as shown in Table 1 , and the lateral acceleration is considered for the middle point only for simplicity. For the ride quality assessment, frequency weighting to allow for human susceptibility is often used, but here (and also for the vertical acceleration problem in Section 4) the unweighted r.m.s. acceleration has been calculated so as not to obscure any undesirable effects that might emerge via the introduction of unconventional suspension devices. 
Table 1 Parameters and default settings of the two-axle vehicle plan view model described by Equations (1) $-(6)$.

\begin{tabular}{|c|c|c|c|}
\hline Symbol & Parameter & Unit & Nominal Value \\
\hline$V$ & Vehicle speed & $\mathrm{ms}^{-1}$ & 31 \\
\hline$m_{w}$ & Wheelset mass & $\mathrm{kg}$ & 1250 \\
\hline$I_{w}$ & Wheelset yaw inertia & $\mathrm{kgm}^{2}$ & 700 \\
\hline$m_{v}$ & Vehicle body mass & $\mathrm{kg}$ & 30000 \\
\hline$I_{v}$ & Vehicle body yaw inertia & $\mathrm{kgm}^{2}$ & 558800 \\
\hline$r_{0}$ & Wheel radius & $\mathrm{m}$ & 0.45 \\
\hline$\lambda$ & Wheel conicity & - & 0.2 \\
\hline$f_{11}, f_{22}$ & Longitudinal and lateral creepage coefficients & $\mathrm{N}$ & $1 \times 10^{7}$ \\
\hline$l_{w x}$ & Half wheelset spacing of the vehicle & $\mathrm{m}$ & 4.5 \\
\hline$l_{w y}$ & Half gauge of weelset & $\mathrm{m}$ & 0.7 \\
\hline$l_{x}$ & $\begin{array}{l}\text { Semi-lateral spacing of longitudinal stiffness per axle } \\
\text { box }\end{array}$ & $\mathrm{m}$ & 1 \\
\hline$K_{x}$ & Primary longitudinal stiffness per axle box & $\mathrm{Nm}^{-1}$ & $1 \times 10^{6}$ \\
\hline$C_{x}$ & Primary longitudinal damping per axle box & $\mathrm{Nsm}^{-1}$ & $4 \times 10^{3}$ \\
\hline$y_{t 1}, y_{t 2}$ & $\begin{array}{l}\text { Straight track lateral stochastic displacement at the } \\
\text { front and rear wheelsets }\end{array}$ & $\mathrm{m}$ & - \\
\hline$g$ & gravity & $\mathrm{ms}^{-2}$ & 9.8 \\
\hline$A_{l}$ & Lateral track roughness factor & $\mathrm{m}$ & $1.886 \times 10^{-9}$ \\
\hline$K_{l}$ & $\begin{array}{l}\text { Lateral stiffness per axle box (parallel spring stiffness } \\
\text { in Figure } 2 \text { ) }\end{array}$ & $\mathrm{Nm}^{-1}$ & $2.555 \times 10^{5}$ \\
\hline
\end{tabular}


Table 2 Optimisation results for minimising $J_{1, y}$ with the suspension layouts $\mathrm{S} 1-\mathrm{S} 4$ when $V=31 \mathrm{~m} / \mathrm{s}$.

\begin{tabular}{llll}
\hline Layouts & $\begin{array}{l}\text { Minimised } \\
J_{1, y}\left(\mathrm{~m} / \mathrm{s}^{2}\right)\end{array}$ & $\begin{array}{l}\text { Imprv. } \\
(\%)\end{array}$ & Parameter values $(\mathrm{N} / \mathrm{m}, \mathrm{Ns} / \mathrm{m}, \mathrm{kg})$ \\
\hline$S 1$ & 0.0959 & - & $k_{1}=\infty, c_{1}=1.64 \times 10^{4}$ \\
$S 2$ & 0.069 & 28 & $k_{1}=4.535 \times 10^{5}, c_{1}=4.1 \times 10^{4}, b_{1}=1.2 \times 10^{3}$ \\
$S 3$ & 0.0938 & 2.2 & $k_{1}=\infty, c_{1}=1.685 \times 10^{4}, b_{1}=1.035 \times 10^{4}$ \\
$S 4$ & 0.0569 & 40.7 & $k_{1}=3.15 \times 10^{5}, c_{1}=5 \times 10^{4}, b_{1}=6.8 \times 10^{3}$, \\
& & & $b_{2}=1095$ \\
\hline
\end{tabular}

\subsection{Performance Benefits Related to Minimising the Lateral Body Acceleration $J_{1, y}$}

We keep the static spring stiffness $K=K_{l}$, (the default static stiffness in the lateral direction shown in Table 1) and optimise over the remaining suspension elements in the lateral direction to minimise $J_{1, y}$. The vehicle speed and other parameters are kept at the nominal values as in Table 1. We first optimise over S1-S4. The results are summarised in Table 2. For all the optimisations carried out in the present paper, we use the matlab command patternsearch first, and then fminsearch for fine tune of the parameters. It can be seen that the parallel inerter-damper layout (S2) provides more improvement than the series inerter-damper layout (S3). The extra spring in series with $c_{1}$ in $\mathrm{S} 1$ and $\mathrm{S} 3$ worsens the ride comfort index $J_{1, y}$, hence the optimum parameter value of $k_{1}$ for these two layouts tends to infinity (see Table 2). On the other hand, $k_{1}$ turns out to be useful to improve $J_{1, y}$ performance in $\mathrm{S} 2$ and $\mathrm{S} 4$, where the percentage improvements compared with default layout S1 are 28 and 40.7, respectively.

We then optimise over the structures shown in Figure 4. It can be seen from the optimisation results in Table 3 that for $\mathrm{S}^{\prime}$ and $\mathrm{S} 4^{\prime}$, the percentage improvements are not reduced much compared to $\mathrm{S} 2$ and $\mathrm{S} 4$ in Table 2, respectively. For S3', the elastic effect of the inerter device (parallel $k_{b_{1}}$ and $c_{b_{1}}$ ) turns out to be helpful, the percentage improvement increasing from 2.2 to 13.3 compared with S3 in Table 2.

The lateral body accelerations across all velocities for the four schemes in Tables 3 are shown in Figure 6 . It can be seen that the ride comfort can be largely improved at most speeds, except for some (middle range) 
Table 3 Optimisation results for minimising $J_{1, y}$ with the suspension layouts shown in Figure 4 , where $k_{c_{1}}$, $k_{b_{1}}, k_{b_{2}} \leq k_{\max } ; c_{b_{1}}, c_{b_{2}} \leq c_{\max }$ and $c_{1}, b_{1}, b_{2}$ being physically realisable, and $V=31 \mathrm{~m} / \mathrm{s}$.

\begin{tabular}{|c|c|c|c|}
\hline Layouts & $\begin{array}{l}\text { Minimised } \\
J_{1, y}\left(\mathrm{~m} / \mathrm{s}^{2}\right)\end{array}$ & $\begin{array}{l}\text { Imprv. } \\
(\%)\end{array}$ & Parameter values $(\mathrm{N} / \mathrm{m}, \mathrm{Ns} / \mathrm{m}, \mathrm{kg})$ \\
\hline $\mathrm{S} 1^{\prime}$ & 0.0996 & - & $k_{c_{1}}=k_{\max }, c_{1}=1.59 \times 10^{4}$ \\
\hline $\mathrm{S} 2^{\prime}$ & 0.0734 & 26.3 & $\begin{array}{l}k_{c_{1}}=4.19 \times 10^{5}, c_{1}=3.45 \times 10^{4}, k_{b_{1}}=k_{\max }, c_{b_{1}}=c_{\max } \\
b_{1}=898\end{array}$ \\
\hline $\mathrm{S} 3^{\prime}$ & 0.0864 & 13.3 & $\begin{array}{l}k_{c_{1}}=k_{\max }, c_{1}=3.33 \times 10^{4}, k_{b_{1}}=1.61 \times 10^{5}, c_{b_{1}}=c_{\max } \\
b_{1}=3.46 \times 10^{3}\end{array}$ \\
\hline $\mathrm{S} 4^{\prime}$ & 0.0608 & 39 & $\begin{array}{l}k_{c_{1}}=5.87 \times 10^{5}, c_{1}=4.33 \times 10^{4}, k_{b_{1}}=3.47 \times 10^{6}, c_{b_{1}}= \\
500, b_{1}=5.87 \times 10^{3}, k_{b_{2}}=k_{\max }, c_{b_{2}}=c_{\max }, b_{2}=811\end{array}$ \\
\hline
\end{tabular}

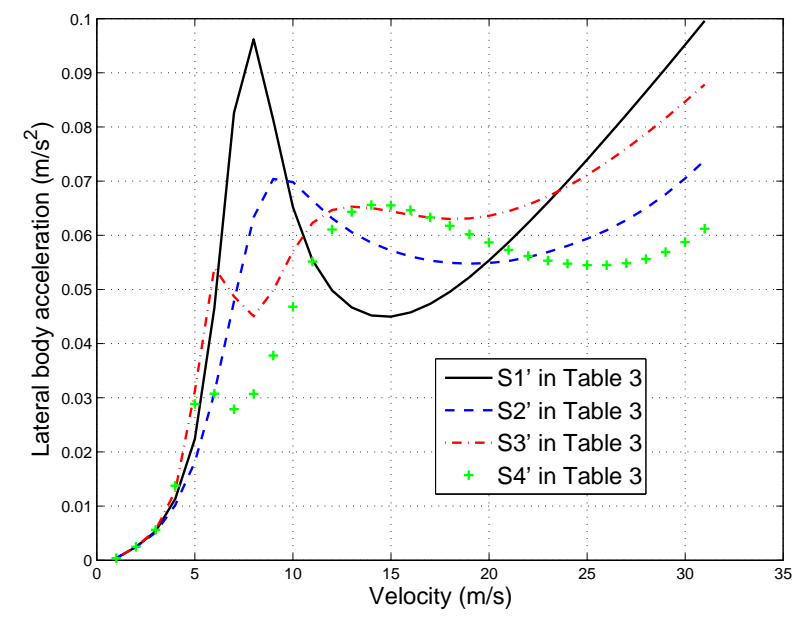

Fig. 6 Lateral body acceleration vs. vehicle speed for the four layouts shown in Figure 4 and parameter values corresponding to Table 3 . 


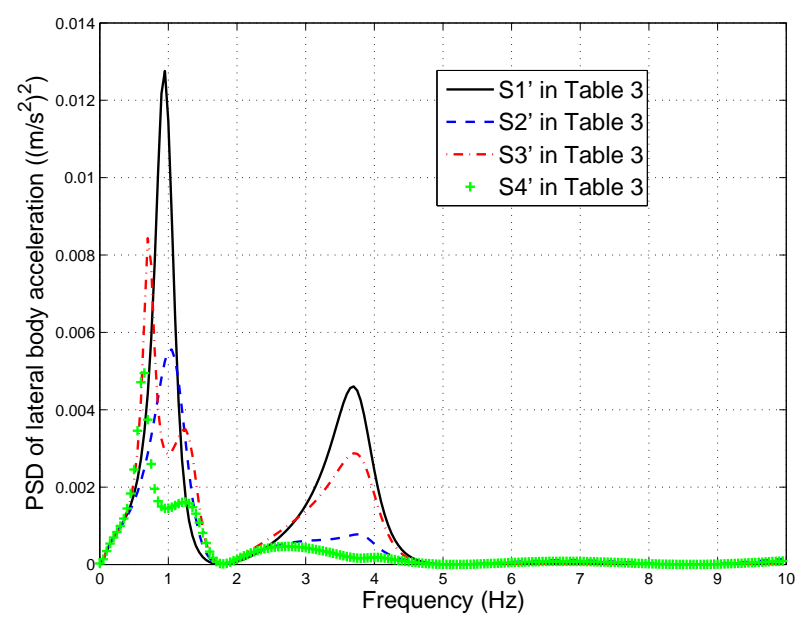

Fig. 7 Power spectral density of lateral body acceleration under the excitation from random track irregularity velocity input for the four layouts shown in Figure 4 and parameter values corresponding to Tables 3.

\section{Bode Diagram}
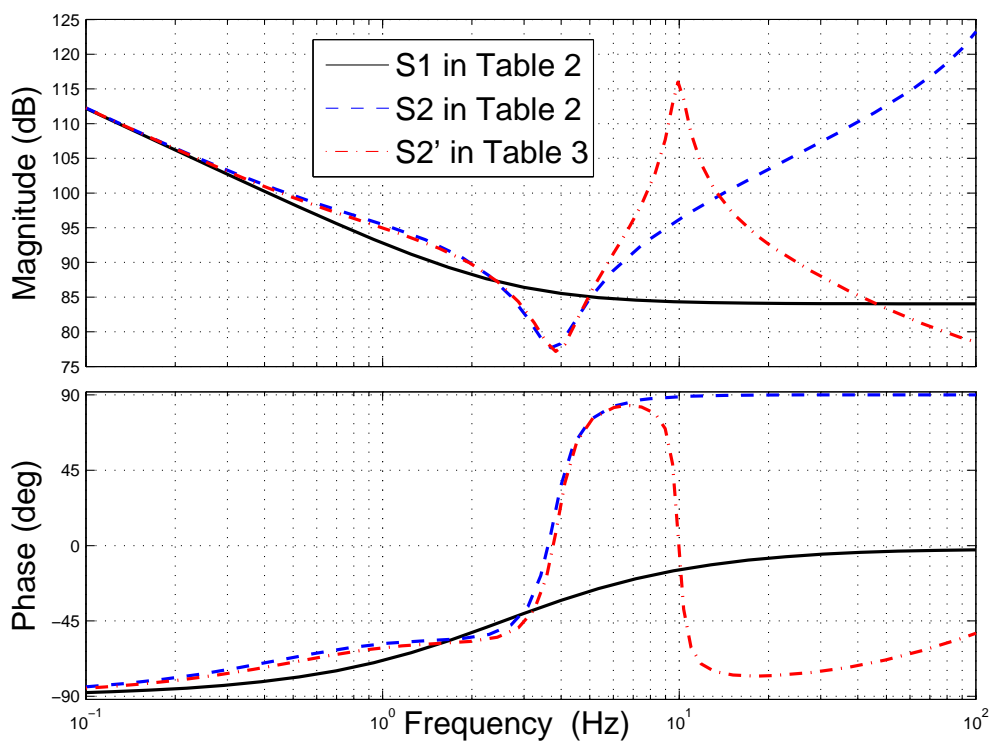

Fig. 8 Bode plot of the mechanical admittance $Y(s)$ for layouts $\mathrm{S} 1, \mathrm{~S} 2$ and $\mathrm{S} 2^{\prime}$ with parameter values according to Tables 2 and 3 . 
velocity values. This should not cause a problem because we are mostly concerned with the ride comfort at the nominal speed $V=31 \mathrm{~m} / \mathrm{s}$. Also the values of $J_{1, y}$ around middle range of velocities are much lower in comparison with high velocities. Figure 7 compares the power spectral density (PSD) of the vehicle body lateral acceleration for the four schemes in Table 3 with $V=31 \mathrm{~m} / \mathrm{s}$. Decreased PSD for S2', $\mathrm{S}^{\prime}$ and $\mathrm{S}^{\prime}$ over $\mathrm{S}^{\prime}$ can be observed, especially the peaks of the curve around 1 and $4 \mathrm{~Hz}$ are reduced. As pointed out in [24] and [25, Chapter 10], the human body is more sensitive to lower frequency (around $1 \mathrm{~Hz}$ ) vibrations in the lateral direction according to BS6841, so the percentage improvement would be even bigger if frequency weighting is used.

The big improvement obtained in Table 3 can be seen also from the Bode plot of the admittance function $Y(s)$. Here we compare $\mathrm{S} 1, \mathrm{~S} 2$ in Table 2 and $\mathrm{S} 2^{\prime}$ in Table 3 as an example. It can be seen from Figure 8 that the damper series spring $k_{1}$ and the parallel inerter $b_{1}$ in S2 provides magnitude and phase changes in the middle frequency range. However, due to the parallel connected inerter $b_{1}$, the magnitude increases at $+20 \mathrm{~dB} / \mathrm{dec}$ for the frequencies above $10 \mathrm{~Hz}$. This will transmit high frequency vibrations and is not desirable. With elastic effects being considered in $\mathrm{S}^{\prime}$, the magnitude becomes $-20 \mathrm{~dB} / \mathrm{dec}$ around $10 \mathrm{~Hz}$ and eventually becomes flat at a much higher frequency. The peak of the magnitude plot for $\mathrm{S}^{\prime}$ is at the oscillation frequency of the inerter device (Figure 3(a)). It can be checked that these elastic effects can also improve the high frequency performance for $\mathrm{S} 3^{\prime}$ and $\mathrm{S} 4^{\prime}$ substantially in a similar way.

We further checked the sensitivity of $J_{1, y}$ to the suspension parameters for $\mathrm{S} 2^{\prime}$ and $\mathrm{S} 4^{\prime}$ in Table 3 . For quantitative comparison, the sensitivity of ride comfort to a suspension parameter (e.g. $c_{1}$ ) is defined as follows $[26]$ :

$$
S_{J}=\frac{d\left(J_{1, y}\right) /\left(J_{1, y}\right)}{d\left(c_{1}\right) / c_{1}} \approx \frac{\Delta J_{1, y}}{\Delta c_{1}} \frac{c_{1}}{J_{1, y}} .
$$

The sensitivities of $J_{1, y}$ to $c_{1}$ and $b_{1}$ are shown in Figure 9 . It can be seen that in general the sensitivity $S_{J}$ is small (always below 1). Furthermore, $J_{1, y}$ is more sensitive to the change of $b_{1}$ than $c_{1}$. Same is also true for $S 4^{\prime}$ in Table 3 . 


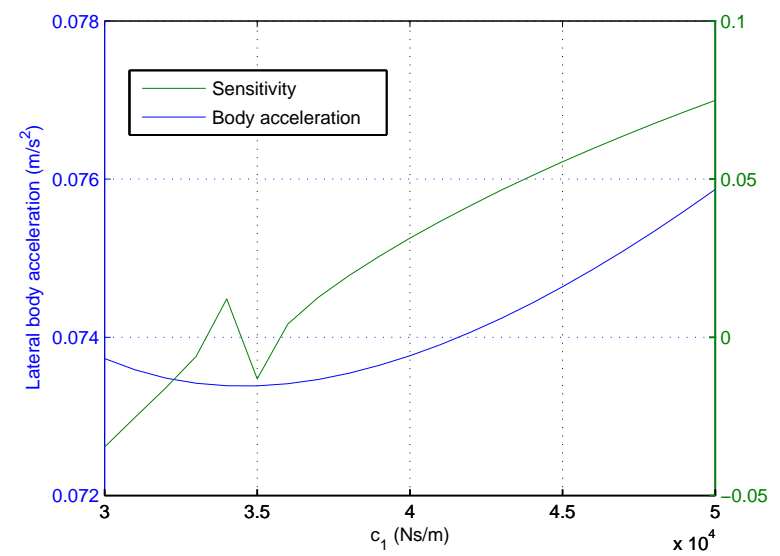

(a)

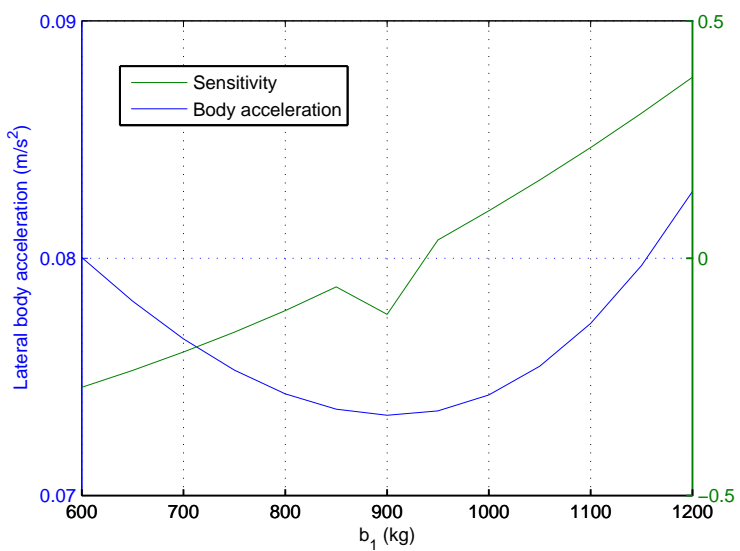

(b)

Fig. 9 Sensitivity of $J_{1, y}$ to suspension parameters $c_{1}$ and $b_{1}$ for $S 2^{\prime}$ in Table 3 .

\section{Passive Suspensions in the Vertical Direction}

In this section, the ride quality improvement in the vertical direction by passive suspensions incorporating the inerter device is investigated. We go further than [4] by considering more realistic suspension layouts and carrying out optimisations in a more systematic manner.

\subsection{Two-Axle Railway Vehicle Side View Model and Track Inputs}

The side view model (with bounce and pitch modes) [3] shown in Figure 10 is considered. This model consists of a vehicle body with mass $m$ and pitch inertia $J$, two candidate suspension layouts with the same admittance $Y(s)$, where $z$ and $\theta$ are the vertical position of the centre of the mass and pitch angle, $z_{t 1}$ and $z_{t 2}$ are the vertical movements of the leading and trailing wheelsets, which are also the track inputs to the system. We take $z_{t 2}(t)=z_{t 1}\left(t-L V^{-1}\right)$ where $L$ is the distance between the two wheelsets and $V$ is the vehicle speed. The vehicle body bending mode is not included so that the fundamental potential of using inerters can be assessed. The mathematical model can be described as follows

$$
\begin{aligned}
m s^{2} \hat{z} & =s Y(s)\left(\hat{z}_{t 1}-\hat{z}\right)+s Y(s)\left(\hat{z}_{t 2}-\hat{z}\right), \\
J s^{2} \hat{\theta} & =\frac{L}{2} s Y(s)\left(-\hat{z}_{t 1}-\frac{L}{2} \hat{\theta}\right)+\frac{L}{2} s Y(s)\left(\hat{z}_{t 2}-\frac{L}{2} \hat{\theta}\right),
\end{aligned}
$$

where $\hat{z}$ denotes the Laplace transform of $z(t)$, etc. 


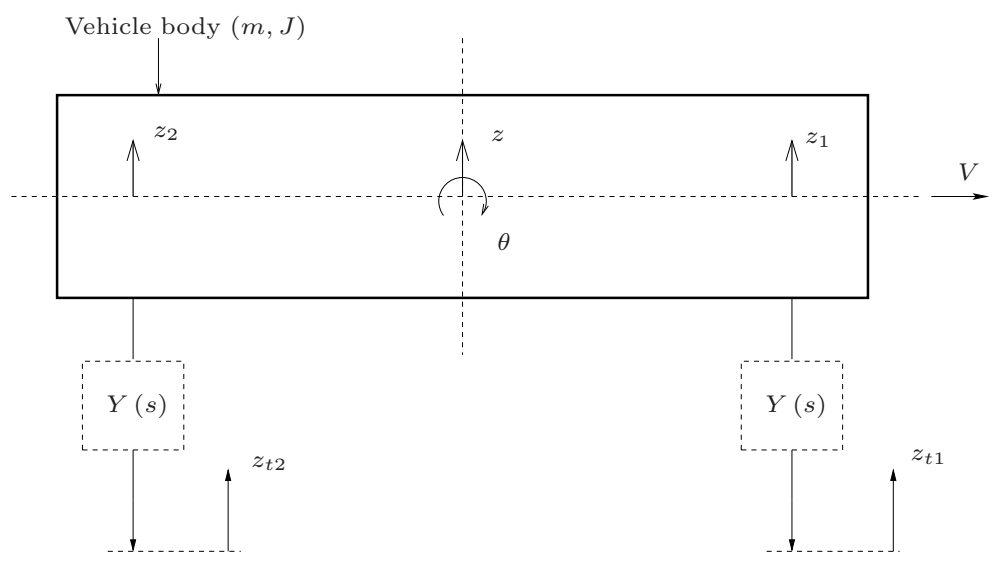

Fig. 10 Side view of a two-axle train model.

For random track input data representing vertical track irregularities, we define $z_{t 1}(t)$ to be the output of a first order filter $H_{2}(s)=1 /(0.03185 s+1)$ (with cutoff frequency around $5 \mathrm{~Hz}$ ) whose input is a process with a single sided power spectrum given by

$S_{s}\left(f_{s}\right)=\frac{A_{v}}{f_{s}^{2}}$

in which $A_{v}$ is the track roughness factor while $f_{s}$ is a spatial frequency in cycles/metre. In this paper, the evaluation of ride quality is assessed by the body accelerations at the leading (L), middle (M) and trailing (T) positions (respectively $z_{1}, z$ and $z_{2}$ according to Figure 10), and is quantified in terms of the root mean square (r.m.s.) acceleration $J_{1, z}$ as expressed by

$$
J_{1, z}^{2}=\int_{0}^{\infty}\left(G_{\dot{z}_{t 1}}(j \omega) H(j \omega)\right)^{2} \dot{S}_{z} d \omega \approx \Delta f \dot{S}_{z} \sum_{\omega=0.01}^{30 \pi}\left(G_{\dot{z}_{t 1}}(j \omega) H(j \omega)\right)^{2}
$$

where

$$
\dot{S}_{z}=4 \pi^{2} A_{v} V,\left(m s^{-1}\right)^{2}(\mathrm{rad} / \mathrm{s})^{-1}
$$

and $G_{\dot{z}_{t 1}}$ represents the transfer function from the track velocity input $\dot{z}_{t 1}$ to the accelerations $\ddot{z}_{1}, \ddot{z}$ or $\ddot{z}_{2}$ at the L, M or T positions. The nominal parameter values are shown in Table 4, which are the same as in [3].

\subsection{Performance Benefits Related to Minimising the Vertical Body Accelera- tion $J_{1, z}$}

For each of the L, M and T positions, $J_{1, z}$ is minimised with the suspension elements in Figure 2. We keep the spring stiffnesses $K=K_{v}$ (the default static stiffness in the vertical direction shown in Table 4) and 
Table 4 Parameters and default settings of the two-axle vehicle side view model described by Equations (8) - (9).

\begin{tabular}{llll}
\hline Symbol & Parameter & Unit & Nominal Value \\
\hline$m$ & Vehicle body mass & $\mathrm{kg}$ & $2 \times 10^{4}$ \\
$J$ & Vehicle body pitch inertia & $\mathrm{kgm}^{2}$ & $3.2 \times 10^{5}$ \\
$L$ & Distance between the two wheelsets & $\mathrm{m}$ & 9 \\
$A_{v}$ & Vertical track roughness factor & $\mathrm{m}$ & $2.5 \times 10^{-7}$ \\
$K_{v}$ & Vertical static stiffness (parallel spring stiffness in & $\mathrm{Nm}^{-1}$ & $3.5 \times 10^{5}$ \\
& Figure 2) & & \\
\hline
\end{tabular}

optimise over the remaining parameters to minimise $J_{1, z}$. The vehicle speed $V$ is the same as in Table 1 and other parameters are kept at the nominal values shown in Table 4. We first optimise over S1-S4. The results are summarised in Tables 5-7. It can be seen that the series inerter-damper layout (S3) provides more advantage than the parallel inerter-damper layout (S2). The extra spring stiffness in series with $c_{1}$ in $\mathrm{S} 1$ and $\mathrm{S} 3$ worsens the $J_{1, z}$ performance at the $\mathrm{L}$ and $\mathrm{T}$ positions (Tables 5 and 7 , respectively), hence the optimum $k_{1}$ value tends to infinity. On the other hand, $k_{1}$ turns out to be useful for S2 and S4 at L, M and $\mathrm{T}$ positions. It should be noted that for the $\mathrm{M}$ position, a very low value of $k_{1}$ for $\mathrm{S} 3$ and $\mathrm{S} 4$ provides a big improvement (in Table 6). However, it can be checked that $J_{1, z}$ for the $\mathrm{L}$ and $\mathrm{T}$ positions will be doubled with these two schemes, hence these are not useful choices. It should be noted that due to the delay between the track inputs to the front and rear wheelsets, the optimised results for the $\mathrm{L}$ and $\mathrm{T}$ positions are different from each other.

We then optimise over the structures shown in Figure 4 for ride quality at the $\mathrm{T}$ position. It can be seen from Table 8 that due to the elastic effects, the improvement for S2' reduced to almost 0 . However, for S $3^{\prime}$ and $\mathrm{S} 4^{\prime}$, the percentage improvements are not changed much compared to S3 and S4 in Table 7. Also, with these schemes, $J_{1, z}$ at the $\mathrm{L}$ and M positions improve by a similar amount (see Table 8).

Figure 11 compares the power spectral density (PSD) of the vehicle body accelerations at the T position for three of the four schemes in Table 8. A decreased PSD for layouts $\mathrm{S} 3^{\prime}$ and $\mathrm{S}^{\prime}{ }^{\prime}$ over $\mathrm{S}^{\prime}$, especially around $1-2 \mathrm{~Hz}$, can be observed. It can be seen from [25, Chapter 10] that the frequency range from 0.5 to $12 \mathrm{~Hz}$ is 
Table 5 Optimisation results for minimising $J_{1, z}$ at the leading position with the suspension layouts S1-S4 when $V=31 \mathrm{~m} / \mathrm{s}$.

\begin{tabular}{|c|c|c|c|}
\hline Layout & $\begin{array}{l}\text { Minimised } J_{1, z} \\
\text { at } \mathrm{L}\left(\mathrm{m} / \mathrm{s}^{2}\right)\end{array}$ & $\begin{array}{l}\text { Imprv. } \\
(\%)\end{array}$ & Parameter values $(\mathrm{Ns} / \mathrm{m}, \mathrm{kg})$ \\
\hline$S 1$ & 0.2327 & 0 & $k_{1}=\infty, c_{1}=2.2 \times 10^{4}$ \\
\hline$S 2$ & 0.2242 & 3.7 & $k_{1}=3.64 \times 10^{6}, c_{1}=2.27 \times 10^{4}, b_{1}=280$ \\
\hline$S 3$ & 0.2116 & 9 & $k_{1}=\infty, c_{1}=2.58 \times 10^{4}, b_{1}=6123$ \\
\hline$S 4$ & 0.2017 & 13.32 & $k_{1}=2.1 \times 10^{6}, c_{1}=2.75 \times 10^{4}, b_{1}=5.8 \times 10^{3}, b_{2}=6123$ \\
\hline
\end{tabular}

Table 6 Optimisation results for minimising $J_{1, z}$ at the middle position with the suspension layouts S1-S4 when $V=31 \mathrm{~m} / \mathrm{s}$.

\begin{tabular}{llll}
\hline Layout & $\begin{array}{l}\text { Minimised } \\
J_{1, z}\end{array}$ & $\begin{array}{l}\text { Imprv. } \\
\text { at M }\left(\mathrm{m} / \mathrm{s}^{2}\right)\end{array}$ & Parameter values $(\mathrm{Ns} / \mathrm{m}, \mathrm{kg})$ \\
\hline$S 1$ & 0.1422 & 0 & $k_{1}=\infty, c_{1}=2.65 \times 10^{4}$ \\
$S 2$ & 0.1359 & 4.4 & $k_{1}=2.15 \times 10^{6}, c_{1}=2.97 \times 10^{4}, b_{1}=296$ \\
$S 3$ & 0.1282 & 9.8 & $k_{1}=2.72 \times 10^{5}, c_{1}=5.55 \times 10^{4}, b_{1}=6090$ \\
$S 4$ & 0.1215 & 14.6 & $k_{1}=3 \times 10^{5}, c_{1}=5.8 \times 10^{4}, b_{1}=6700, b_{2}=220$ \\
\hline
\end{tabular}

Table 7 Optimisation results for minimising $J_{1, z}$ at the trailing position with the suspension layouts S1-S4 when $V=31 \mathrm{~m} / \mathrm{s}$.

\begin{tabular}{|c|c|c|c|}
\hline Layout & $\begin{array}{l}\text { Minimised } J_{1, z} \\
\text { at } \mathrm{T}\left(\mathrm{m} / \mathrm{s}^{2}\right)\end{array}$ & $\begin{array}{l}\text { Imprv. } \\
(\%)\end{array}$ & Parameter values (Ns/m, kg) \\
\hline$S 1$ & 0.2702 & 0 & $k_{1}=\infty, c_{1}=3.04 \times 10^{4}$ \\
\hline$S 2$ & 0.2593 & 4 & $k_{1}=3.98 \times 10^{6}, c_{1}=3.2 \times 10^{4}, b_{1}=349$ \\
\hline$S 3$ & 0.2469 & 8.6 & $k_{1}=\infty, c_{1}=3.33 \times 10^{4}, b_{1}=1 \times 10^{4}$ \\
\hline$S 4$ & 0.2322 & 14 & $k_{1}=2.16 \times 10^{6}, c_{1}=3.6 \times 10^{4}, b_{1}=9 \times 10^{3}, b_{2}=339$ \\
\hline
\end{tabular}


Table 8 Optimisation results for minimising $J_{1, z}$ at the trailing position with the suspension layouts shown in Figure 4 , where $k_{c_{1}}, k_{b_{1}}, k_{b_{2}} \leq k_{\max } ; c_{b_{1}}, c_{b_{2}} \leq c_{\max }$ and $c_{1}, b_{1}, b_{2}$ being physically realisable, and $V=31 \mathrm{~m} / \mathrm{s}$.

\begin{tabular}{|c|c|c|c|c|c|}
\hline Layout & $\begin{array}{l}\text { Minimised } \\
J_{1, z} \text { at } \mathrm{T} \\
\left(\mathrm{m} / \mathrm{s}^{2}\right)\end{array}$ & $\begin{array}{l}\text { Imprv. } \\
(\%)\end{array}$ & Parameter values $(\mathrm{Ns} / \mathrm{m}, \mathrm{kg})$ & $\begin{array}{l}J_{1, z} \\
\text { at } \quad \mathrm{L} \\
\left(\mathrm{m} / \mathrm{s}^{2}\right)\end{array}$ & $\begin{array}{l}J_{1, z} \\
\text { at } \mathrm{M} \\
\left(\mathrm{m} / \mathrm{s}^{2}\right)\end{array}$ \\
\hline $\mathrm{S} 1^{\prime}$ & 0.2808 & - & $k_{c_{1}}=k_{\max }, c_{1}=2.98 \times 10^{4}$ & 0.2493 & 0.1465 \\
\hline $\mathrm{S}^{\prime}$ & 0.2799 & 0.3 & $\begin{array}{l}k_{c_{1}}=k_{\max }, c_{1}=2.98 \times 10^{4}, \\
k_{b_{1}}=2.179 \times 10^{5}, c_{b_{1}}=10, b_{1}=6\end{array}$ & 0.2484 & 0.1459 \\
\hline $\mathrm{S} 3^{\prime}$ & 0.2535 & 9.7 & $\begin{array}{l}k_{c_{1}}=k_{\max }, c_{1}=3.43 \times 10^{4} \\
k_{b_{1}}=k_{\max }, c_{b_{1}}=c_{\max }, b_{1}=8232\end{array}$ & 0.2286 & 0.1459 \\
\hline $\mathrm{S} 4^{\prime}$ & 0.2466 & 12.2 & $\begin{array}{l}k_{c_{1}}=k_{\max }, c_{1}=3.62 \times 10^{4}, k_{b_{1}}=1.64 \times 10^{6}, \\
c_{b_{1}}=c_{\max }, b_{1}=7527, k_{b_{2}}=3.68 \times 10^{5}, c_{b_{2}}= \\
c_{\max }, b_{2}=91\end{array}$ & 0.2235 & 0.1417 \\
\hline
\end{tabular}

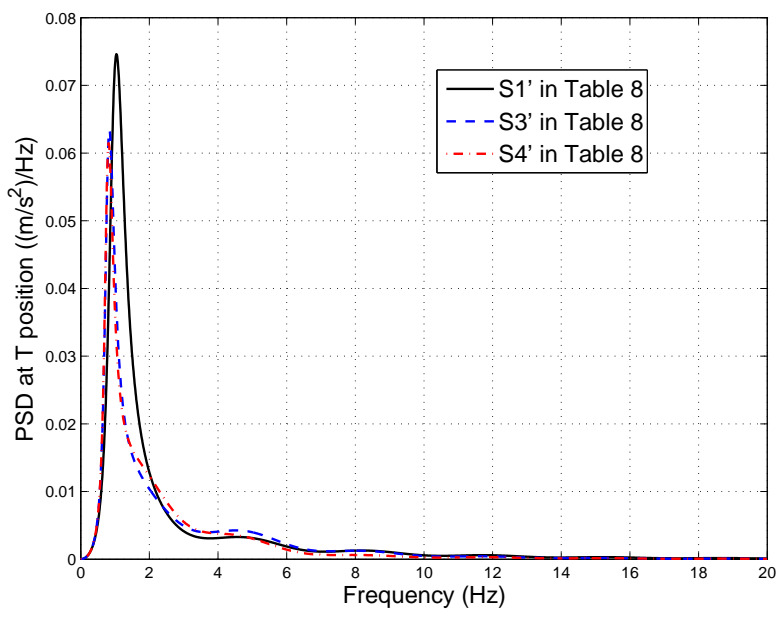

Fig. 11 Power spectral density of vehicle body acceleration at the trailing position (T) under the excitation from random track irregularity velocity input for three of the four layouts shown in Figure 4 and parameter values corresponding to Table 8 . 


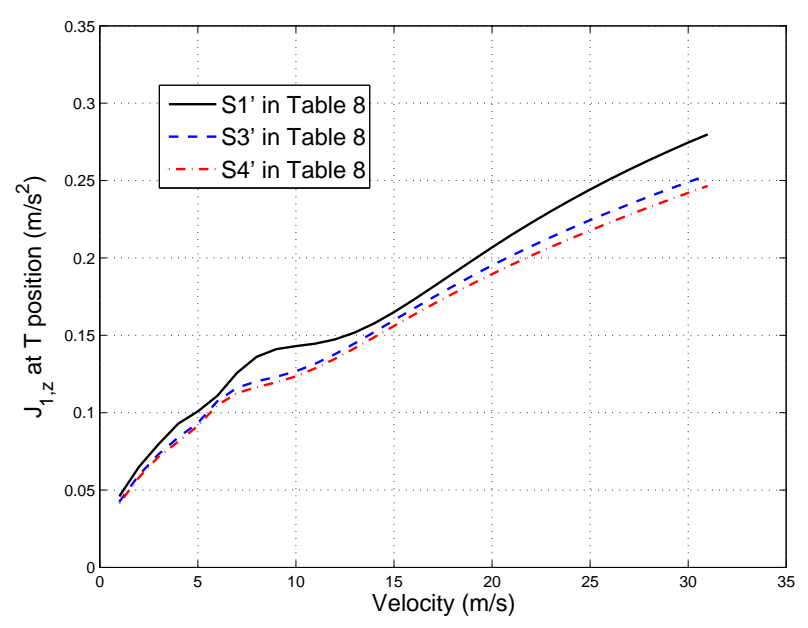

Fig. $12 J_{1, z}$ at the trailing position vs. vehicle speed for three of the four layouts shown in Figure 4 and parameter values corresponding to Table 8 .

the most important according to ISO2631 and BS6841. The vertical body accelerations across all velocities with these three schemes in Table 8 are shown in Figure 12. It can be seen that $J_{1, z}$ at position $\mathrm{T}$ has been improved across all velocities with $\mathrm{S} 3^{\prime}$ and $\mathrm{S} 4^{\prime}$ compared with $\mathrm{S} 1^{\prime}$.

We further checked the sensitivity of $J_{1, z}$ to the suspension parameters for $\mathrm{S} 4^{\prime}$ in Table 8 . For quantitative comparison, the sensitivity of ride comfort to a suspension parameter (e.g. $\left.c_{1}\right)$ is defined as follows [26]:

$S_{J}=\frac{d\left(J_{1, y}\right) /\left(J_{1, y}\right)}{d\left(c_{1}\right) / c_{1}} \approx \frac{\Delta J_{1, y}}{\Delta c_{1}} \frac{c_{1}}{J_{1, y}}$.

The sensitivities of $J_{1, z}$ to $c_{1}, b_{1}$ and $b_{2}$ are shown in Figure 13. It can be seen that in general the sensitivity $S_{J}$ is very small (always below 0.1 ). Furthermore, $J_{1, z}$ is also more sensitive to the change of $c_{1}$ in this case.

\section{Conclusions and General Remarks}

This paper has investigated the potential performance benefit of incorporating inerters in the lateral and vertical suspensions of a two-axle railway vehicle. With simple suspension layouts including elastic effects, we obtain around $39 \%$ improvement for the ride comfort in the lateral direction and $12.2 \%$ improvement in the vertical direction. For the plan view and side view two-axle railway vehicle models we investigated, the following conclusions can also be drawn based on the results obtained. 


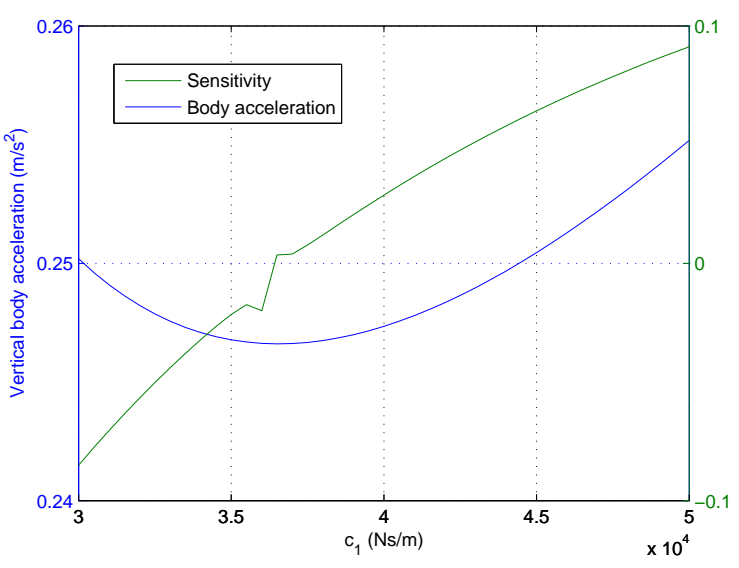

(a)

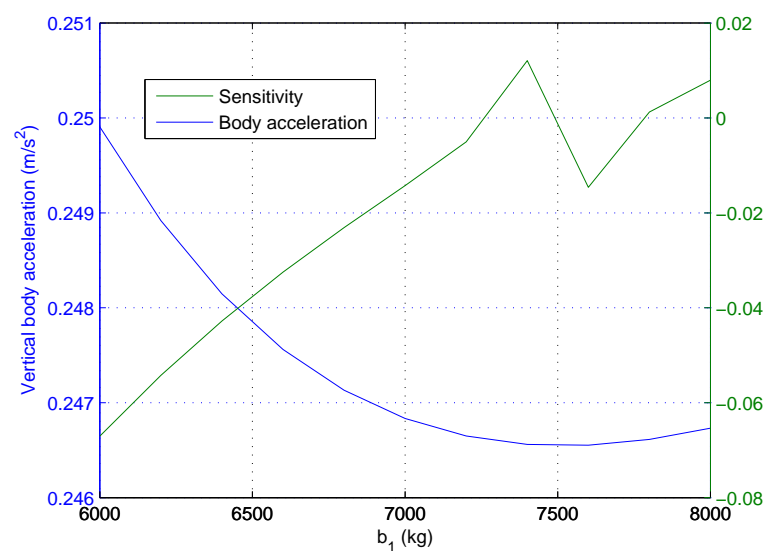

(b)

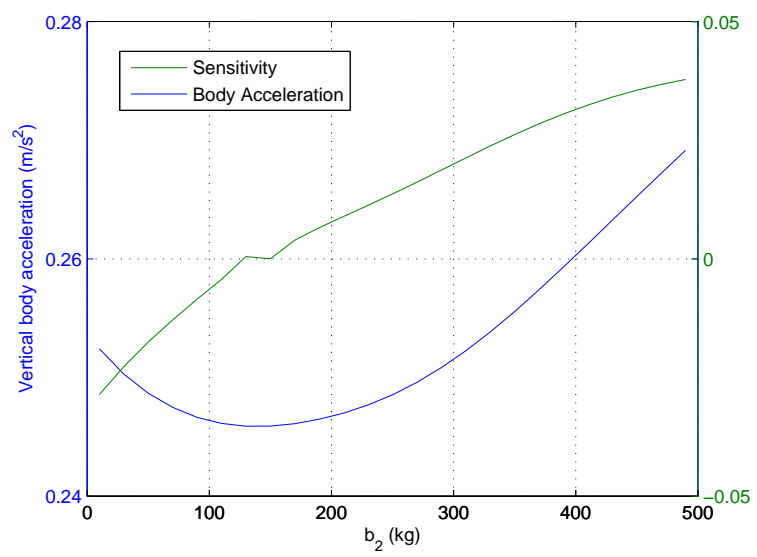

(c)

Fig. 13 Sensitivity of $J_{1, z}$ to suspension parameters $c_{1}, b_{1}$ and $b_{2}$ for $S 4^{\prime}$ in Table 8 . 
1. According to the optimisation results, layout S1 provides optimum ride quality in both lateral and vertical direction when $k_{1}=\infty$ (see Tables 2 and $6-7$ ). This agrees with the findings in [27] for a quarter-car vehicle model, though this may seem counter-intuitive.

2. For both lateral and vertical direction models, when the inerter device is added in parallel, the elastic effect of the damper $c_{1}\left(k_{c_{1}}\right)$ turns out to be helpful to provide better optimum ride quality (e.g. see Tables 2, 3, and 5-7).

3. When the elastic effects are included, the optimum inerter values become smaller (e.g. compare the inerter values for $\mathrm{S} 2-\mathrm{S} 4$ in Tables 2, 7 and for $\mathrm{S}^{\prime}{ }^{\prime}-\mathrm{S} 4^{\prime}$ in Tables 3 and 8).

4. In the lateral direction, when the optimum values of the elastic effects for the parallel inerter are equal to $k_{\max }$ and $c_{\max }$ (S2' and $\mathrm{S}^{\prime}$ in Table 3 ), the ride comfort can be improved substantially. Sufficient values for end-stiffness and dissipation effect are very important, they can keep the oscillation frequency at a higher value and better damping of the inerter device, respectively. For example, if we can design the inerter device with a higher value of damping $\left(c_{b}\right)$, the peak of the magnitude plot for $\mathrm{S}^{\prime}{ }^{\prime}$ in Figure 8 will be further reduced.

5. Systems with suspension layouts $\mathrm{S} 2^{\prime}-\mathrm{S} 4^{\prime}$ have better high frequency performance compared with those with S2-S4 which do not include elastic effects.

6. It should be observed that dampers and inerters (and other elements) can be built in single integrated packages (see e.g. [14]).

Benefits from the inclusion of inerters has been established, so the next steps are to introduce further practicalities as follows.

a. To use measured track data for comparison with results using the synthesised track inputs.

b. To include body flexible modes so that series end-stiffness of dampers and inerters can be more effectively optimised.

c. To compare basic RMS accelerations with appropriate frequency weighted results according to specific industry needs. 


\section{Acknowledgements}

We are grateful for the helpful comments of T.X. Mei, J. Evans and the reviewers. This work was supported by the Engineering and Physical Sciences Research Council [grant number EP/G066477/1]. This was also supported by Universidad de Los Andes, Venezuela and via a departmental scholarship from the School of Electronics, Electrical and Systems Engineering, Loughborough University, UK.

\section{References}

1 Bhiwapurkar M. K., Saran V. H., Harsha S. P., Goel V. K., and Berg M. Effect of magnitudes and directions (mono-axis and multi-axis) of whole body-vibration exposures and subjects postures on the sketching performance. Proceedings of the Institution of Mechanical Engineers, Part F: Journal of Rail and Rapid Transit, 1(225):71-83, January 2011.

2 Goodall Roger and Mei T X. Mechatronic strategies for controlling railway wheelsets with independently rotating wheels. In IEEE/ASME International Conference on Advanced Intelligent Mechatronics Proceedings, pages 225-230, Como, Italy, 2001. IEEE/ASME International Conference on Advanced Intelligent Mechatronics Proceedings.

3 Pacchioni Alessandro, Goodall Roger M., and Bruni Stefano. Active suspension for a two-axle railway vehicle. Vehicle System Dynamics, 48:105-120, 2010.

4 Jiang Jason Zheng, Matamoros-Sanchez Alejandra Z., Goodall Roger M., and Smith M. C. Performance benefit in two-axle railway vehicle suspensions employing inerters. "Developments in Control Theory towards Glocal Control" Li Qiu, Jie Chen, Tetsuya Iwasaki and Hisaya Fujioka (Eds.), 11:99-107, 2012.

5 Smith M. C. Synthesis of mechanical networks: the inerter. IEEE Trans. Automatic Control, 47(10):1648-1662, 2002.

6 Papageorgiou C. and Smith M. C. Positive real synthesis using matrix inequalities for mechanical networks: application to vehicle suspension. IEEE Trans. on Contr. Syst. Tech., 14:423-435, 2006.

7 Smith M. C. and Wang F. C. Performance benefits in passive vehicle suspensions employing inerters. Vehicle System Dynamics, 42:235-237, 2004. 

erter raced in Formula One, 19 August 2008.

9 Evangelou S., Limebeer D. J. N., Sharp R. S., and Smith M. C. Control of motorcycle steering instabilities - passive mechanical compensators incorporating inerters. IEEE Control Systems Magazine, 26(5):78-88, October 2006.

10 Evangelou S., Limebeer D. J. N., Sharp R. S., and Smith M. C. Mechanical steering compensation for high-performance motorcycles. Transactions of ASME, J. of Applied Mechanics, 74:332-346, 2007.

11 Wang F. C., Hong M. F., and Chen C. W. Performance analyses of building suspension control with inerters. pages 3786-3791, New Orleans, LA, USA, Dec. 2007. IEEE Conference on Decision and Control.

12 Wang F.C., Su W.J., and Chen C.W. Building suspensions with inerters. Proceedings of the Institution of Mechanical Engineers, Part C, Journal of Mechanical Engineering Science, 224:1650$1616,2010$.

13 Chen M. Z. Q., Papageorgiou C., Scheibe Frank, Wang F. C., and Smith M. C. The missing mechanical circuit element. IEEE Circuits and Systems Magazine, pages 10-26, First Quarter 2009.

14 McBeath Simon. Shocks to the system. Racecar Engineering, pages 51-54, November 2011.

15 Wang F. C., Liao M. K., Liao B. H., Su W. J., and Chan H. A. The performance improvements of train suspension systems with mechanical networks employing inerters. Vehicle System Dynamics, 47(7):805-830, 2009 .

16 Wang F. C. and Liao M. K. The lateral stability of train suspension systems employing inerters. Vehicle System Dynamics, 48(5):619-643, 2010.

17 Jiang Jason Zheng, Matamoros-Sanchez Alejandra Z., Goodall Roger M., and Smith M. C. Passive suspensions incorporating inerters for railway vehicles. Vehicle System Dynamics:International Journal of Vehicle Mechanics and Mobility, 50(Sup1):263-276, Auguest 2011.

18 Smith M. C. Force-controlling mechanical device. Int. App. No. PCT/GB02/03056, priority date: 4 July 2001, US patent number 7,316,303, European patent no: EP1402327B1. 
19 Glover A. R., Smith M. C., Houghton N. E., and Long P. J. G. Force-controlling hydraulic device. Int. App. No. PCT/GB2010/001491, priority date: 6 August 2009.

20 Gartner B. and Smith M. C. Damping and inertial hydraulic device. Int. App. No. PCT/GB2011/000160, priority date: 5 Feburary 2010.

21 Li Ping, Goodall Roger, Weston Paul, Ling Chung Seng, Goodman Colin, and Robers Clive. Estimation of railway vehicle suspension parameters for condition monitoring. Control Engineering Practice, 15:43-55, 2007.

22 Mei T. X. and Goodall Roger M. Robust control for independently rotating wheelsets on a railway vehicle using practical sensors. IEEE Transactions on control systems technology, 9(4):599607, July 2001.

23 Li Hong. Measuring Systems for Active Steering of Railway Vehicles. PhD thesis, Loughborough University, July 2001.

24 Mansfield Neil J. Human Response to Vibration. CRC Press ISBN: 041528239X, 2004.

25 Iwnicki Simon, editor. Handbook of Railway Vehicle Dynamics. CRC Press ISBN:0849333210, USA, December 2005.

26 Wang F. C. and Hsieh M. R. The use of inerters improves the stability and performance of a full-train model. pages 1-12. International Symposium: Dynamics of Vehilces on Roads and Tracks, August 2009.

27 Scheibe F. and Smith M. C. Analytical solutions for optimal ride comfort and tyre grip for passive vehicle suspensions. Vehicle System Dynamics, 47(10):1229-1252, 2009. 